\title{
AS RELAÇÕES ENTRE PANIZZI E DEWEY: UMA ANÁLISE DISCURSIVA SOBRE SUAS CRIAÇÕES E A BIBLIOTECONOMIA MODERNA.
}

\author{
THE RELATION BETWEEN PANIZZI AND DEWEY: A \\ DISCURSIVE ANALYSIS ABOUT THEIR CREATIONS \\ AND THE MODERN LIBRARIANSHIP.
}

\author{
Gabriela Bazan Pedrão' \\ João Batista Ernesto de Moraes²
}

\begin{abstract}
RESUMO
Introdução: A Biblioteconomia vem se desenvolvendo, principalmente, desde o século XIX com a criação das primeiras escolas e o desenvolvimento de regras e sistemas mais elaborados de organização. Objetivo: O presente artigo tem como objetivo um estudo comparativo entre dois dos mais importantes bibliotecários da história e que trouxeram inovações nesse século. Antony Panizzi, criador do Catálogo dos Livros Impressos do Museu Britânico, mais conhecido como Catálogo de Panizzi, que organizou toda a Biblioteca do Museu Britânico em 1837, e Melvil Dewey, criador da Classificação Decimal Dewey, em 1876, utilizada até hoje e considerada um dos métodos de classificação mais populares em todo mundo. Ambos foram pioneiros na história da Biblioteconomia e na organização da informação, um nos catálogos e o outro nas classificações. Embora tenham modificado áreas diferentes, elas estão relacionadas, e as trajetórias dos bibliotecários têm diversos pontos em comum. Metodologia: Esse estudo discutirá, com a ajuda da análise do discurso e seus teóricos, a importância das criações desses dois bibliotecários e como elas então ligadas e se completam. Resultados: Os dois bibliotecários descritos parecem estar distantes, suas ideias parecem não fazer parte de um mesmo círculo, mas como o presente trabalho mostra, estão intimamente ligadas. Conclusões: As criações de ambos ainda estão presentes nas nossas atividades rotineiras e auxiliaram no desenvolvimento de técnicas e sistemas atuais, mostrando que a Biblioteconomia tem uma base forte em seu passado que auxilia na construção de seu futuro.
\end{abstract}

Descritores: Antony Panizzi. Melvil Dewey. Catálogo. Análise do discurso.

\footnotetext{
1 Doutoranda em Ciência da Informação pela Universidade Estadual Paulista Júlio de Mesquita Filho (Unesp). E-mail: gabriela.bzp@gmail.com

2 Doutor em Estudos Literários pela Universidade Estadual Paulista Júlio de Mesquita Filho (Unesp). Professor da Faculdade de Filosofia e Ciências (Unesp). E-mail: prof.joao@gmail.com
} 
Biblioteconomia.

\section{INTRODUÇÃO}

A organização da informação é algo que existe há séculos. A profissão de bibliotecário vem de antes de Cristo com bibliotecas como a de Alexandria, por exemplo. Mas é possível afirmar que a Biblioteconomia passou a se desenvolver mais rapidamente principalmente no século XIX. A partir desse século foram criadas as primeiras escolas de Biblioteconomia e as técnicas bibliotecárias começaram a adquirir regras e foram sistematizadas (ORTEGA, 2004).

Partindo então do século XIX, foram selecionados dois nomes de grande importância para serem estudados nesse artigo: Antony Panizzi e Melvil Dewey. O primeiro foi bibliotecário da Biblioteca do Museu Britânico, uma das mais importantes do mundo, durante o período de 1831 a 1856 (MILLER, 1967) e lá criou seu famoso Catálogo que mudou a história da Biblioteca e influenciou a catalogação moderna. O segundo, Melvil Dewey, criou a Classificação Decimal Dewey (CDD), solidificou a profissão de bibliotecário e contribuiu para o desenvolvimento da área nos Estados Unidos, entre 1876 e 1906 (WIEGAND, 1996).

Apesar de atuarem de maneiras diferentes, um criou um catálogo e outro uma classificação, essas são áreas que se complementam, pois, a classificação é um dos campos que compõe a catalogação de uma obra. Ambos deixaram um legado muito importante para a Biblioteconomia moderna e já levaram títulos como 'pai da Biblioteconomia' e 'o primeiro bibliotecário entre os bibliotecários'. Com isso em mente, esse artigo tem como objetivo estudar brevemente a história dos bibliotecários, levantar as semelhanças entre esses dois profissionais e suas conquistas e avalia-las sob a ótica da análise do discurso, tornando possível uma reflexão sobre esses legados para a Biblioteconomia atual.

A análise do discurso (AD) é importante nesse caso, pois ela trabalha com maneiras de significar e considera a produção de sentido enquanto parte da vida de um sujeito. Essa parte pode estar no meio individual ou enquanto membros de uma determinada forma de sociedade (ORLANDI, 2007). Nesse trabalho 
ambas as partes serão consideradas: as individuais, estudando as histórias dos bibliotecários em questão, e enquanto sociedade, onde será trabalhado o legado de ambos na Biblioteconomia, que nada mais é que uma comunidade específica de profissionais.

Orlandi (2007) diz que a AD não busca responder questões de 'o quê', mas sim 'como'. Dessa forma, esse trabalho busca responder as questões de como esses bibliotecários estão interligados e como seus trabalhos completamse em uma época que foi de grande importância para a Biblioteconomia.

Esse trabalho justifica-se na importância do estudo histórico da área. Muitas práticas que utilizamos atualmente vêm desse crescimento que aconteceu durante o século XIX e das inovações propostas por esses bibliotecários. Panizzi nos deixou um importante legado na catalogação como, por exemplo, direcionamentos para a catalogação de obras anônimas. Já Dewey deixou como herança sua classificação, a CDD, amplamente utilizada até hoje.

Como metodologia desse estudo, será utilizada a $A D$ que apresenta ferramentas competentes para que seja possível realizar uma reflexão acerca dessas duas trajetórias. Através do materialismo histórico empregado pela $A D$ será possível compreender a formação e a transformação social que esses dois bibliotecários construíram.

O estudo começará com uma breve biografia de ambos os bibliotecários, para que seja possível criar um contexto que será seguido de uma discussão de suas ideias. Após essa discussão o trabalho terá uma pequena reflexão nas considerações finais.

\section{ANTONY PANIZZI}

Antonio Genesio Maria Panizzi nasceu em Brescello, na Itália, em 1797. Formou-se em Direito em 1818 e, ao mesmo tempo em que trabalhava como advogado, era membro de um grupo secreto revolucionário que lutava pela libertação da Itália contra o domínio Austríaco e em prol da unificação italiana (FAGAN, 2012). Em 1822, Panizzi foi preso por suspeitas de seu envolvimento com atividades revolucionárias e logo depois julgado como membro da 
revolução. Em 1823, foi condenado à morte por sua participação na revolução e fugiu para Suíça. Não permaneceu muito tempo no país e logo precisou fugir novamente, mudando-se definitivamente para Inglaterra, onde passou a ser conhecido como Anthony Panizzi (FAGAN, 2012). Vivendo em Liverpool ele aprendeu inglês e passou a dar aulas de italiano, até que em 1831, por indicação, conseguiu um cargo na Biblioteca do Museu Britânico como assistente de bibliotecário, no departamento de livros impressos.

Quando entrou na Biblioteca, Panizzi afirmou que a qualidade do acervo estava muito abaixo do que se era esperado para uma biblioteca de um país como a Inglaterra. Assim um de seus esforços durante a vida foi a tentativa de melhorar e engrandecer o acervo (MILLER, 1967). Ele se destacou em seu trabalho como auxiliar, até que em 1834 foi indicado para um trabalho de maior responsabilidade.

Desde 1834 a Biblioteca Britânica passava por tentativas de reformulação e construção de um catálogo novo e melhor (MILLER, 1967). Mas até então as tentativas haviam sido falhas, principalmente por desinteresse dos diretores da Biblioteca. Panizzi, percebendo esse descaso, resolveu pensar em novas formas de organização que poderiam trazer soluções para a desordem presente (MILLER, 1967). Ele participou ativamente de sessões judiciais que investigavam a administração da Biblioteca e se esforçou para que suas ideias fossem ouvidas.

Panizzi chegou a aplicar questionários sobre organização e acervo para o público e para outras bibliotecas da Inglaterra, e em 1835, viajou pela Europa para conhecer outras instituições e como eram organizadas (MILLER, 1967). Ao retornar foi entrevistado pelos diretores da biblioteca sobre suas descobertas e viu uma oportunidade para colocar suas ideias em prática. Em 1837 com as investigações judiciais encerradas, os diretores nomearam Panizzi como responsável pela sessão de livros impressos e a partir desse momento ele começou a desenvolver o tão sonhado catálogo. Contando com a ajuda de seus assistentes, ele criou 91 regras de catalogação, a fim de solucionar pontualmente os problemas de busca e recuperação da informação no acervo da Biblioteca. 
Suas regras inseriram dados como nome do autor, título, assunto e diretrizes a serem tomadas em caso de obras anônimas, por exemplo. Dada a desorganização anterior do acervo e da Biblioteca, as regras de Panizzi foram amplamente aclamadas, fazendo com que o próprio acreditasse que elas seriam à prova de erros.

O catálogo gerou acaloradas discussões após sua publicação em 1841. Os usuários acreditavam que alguns ajustes eram necessários, mas Panizzi e os bibliotecários que trabalhavam com ele discordavam, eles acreditavam que o trabalho final era completo e funcional. Apesar das controvérsias e problemas, o Catálogo saiu-se bem e tornou-se um dos primeiros modelos de catálogos modernos.

Sua trajetória na Biblioteca do Museu Britânico foi marcada, além da criação do Catálogo, por outras mudanças significativas. Enquanto foi responsável pelo setor de livros impressos, Panizzi conseguiu tornar o acervo mais rico através de várias aquisições (MILLER, 1967). As prioridades eram livros raros, incunábulos e obras em outros idiomas, visando um acervo rico e variado, que representasse um conhecimento universal. Em dezesseis anos o acervo cresceu de 230.000 livros para 470.000 e durante sua administração, Panizzi também fez a primeira ampliação da Biblioteca, que não comportava mais o acervo e seus usuários satisfatoriamente (MILLER, 1967).

Em 1865, Panizzi começou a anunciar sua aposentadoria por problemas de saúde e por acreditar que já não era mais capaz de sustentar o cargo de bibliotecário chefe. Por pedidos do comitê da Biblioteca, ele ficou no cargo por mais alguns meses, até que em julho de 1865 ele apresentou oficialmente seu sucessor e se retirou do cargo.

Panizzi viveu após a aposentadoria o mais próximo que pode da Biblioteca, que afirmava ser impossível se distanciar, e faleceu em abril de 1879, com 82 anos.

Seu legado para a Biblioteconomia foi muito importante, começando pelo crescimento e acervo da Biblioteca do Museu Britânico, que cresceram em tamanho e qualidade durante sua gestão, até seu famoso Catálogo. O Catálogo dos Livros Impressos do Museu Britânico, mais conhecido como Catálogo de 
Panizzi, influenciou diversos outros catálogos que vieram em seguida, como 0 catálogo do Instituto Smtihsonian, contemporâneo a ele, em 1853 (FATTAHI, 1997). O bibliotecário Charles C. Jewett se baseou em Panizzi para desenvolver trinta e três regras de catalogação que foram usadas no Instituto. Outros influenciados foram o bibliotecário e pesquisador Seymour Lubetzky, na construção do 'Manual of Descriptive Cataloguing', em 1943; Charles A. Cutter no desenvolvimento de 'Rules for Dictionary Catalogue', em 1937 e a 'Anglo American Cataloguing Rules (AACR), desenvolvida pela Associação AngloAmericana de Catalogação em 1969 (FATTAHI, 1997).

\section{MELVIL DEWEY}

Melville Louis Kossuth Dewey, mais conhecido como Melvil Dewey, nasceu em Nova York em 1851. Desde sua infância, Dewey sempre mostrou interesse em simplificar e organizar o universo ao seu redor, desde o armário de despensa de sua mãe até sua forma de escrever. Começou modificando seu próprio nome para Melvil e gostava de trabalhar com métodos de escrita simplificada, transformando palavras de acordo com seus sons e criando abreviações (WIEGAND, 1996).

Dewey frequentou a Alfred University e o Amherst College, e após terminar sua graduação começou a trabalhar na biblioteca de Amherst como assistente de alunos. Nessa época, com vinte e um anos, ele desenvolveu seu próprio sistema de classificação: a Classificação Decimal Dewey (CDD), que viria a ser uma das mais importantes na história da Biblioteconomia (WIEGAND, 1996). A classificação foi publicada anonimamente e era intitulada 'Classification and Subject Índex for Cataloguing and Arranging the Books and Pamphlets of a Library', sua segunda edição foi publicada em 1885, com indicação de autoria e o nome de 'Decimal Classification and Relative Índex'. Apenas em sua décima sexta edição a classificação passou a se chamar 'Classificação Decimal Dewey'. Através dessa classificação, Dewey reorganizou a biblioteca de Amherst e em 1876, oficializou sua criação registrando os direitos autorais e dando origem a segunda edição mencionada (WIEGAND, 1996). 
A CDD é um sistema de classificação que organiza o conhecimento em dez classes através de números decimais, criando uma organização numérica e hierárquica. A organização é feita por assuntos separados em grandes classes e para criar especificidade é possível relacionar e combinar assuntos (OCLC, 2016). As grandes classes são:

- 000 Generalidades

- 100 Filosofia e Psicologia

- 200 Religião

- 300 Ciências sociais

- 400 Línguas

- 500 Ciências puras

- 600 Ciências aplicadas

- 700 Artes

- 800 Literatura

- 900 História e Geografia

Dentro de cada grande área há divisões centesimais e na casa dos milhares que permitem as combinações que dão origem às especificidades. Atualmente a classificação está em sua vigésima terceira edição.

Em 1877, Dewey fundou e tornou-se editor do The Library Journal, que influenciou o desenvolvimento de diversas bibliotecas nos Estados Unidos através de conteúdos específicos da área e a disseminação das ideias de Dewey. Paralelo a isso ele também ajudou a fundar a Associação de Bibliotecas Americanas, uma associação que começou com a missão de difundir, promover e desenvolver a profissão. A associação permanece em funcionamento até os dias atuais e Dewey foi secretário de 1876 a 1890 e depois presidente de 1890 a 1894 (WIEGAND, 1996). É notável que Dewey era um pioneiro e um ativista em tudo que se dizia respeito à profissão de bibliotecário e seu universo. Além desses dois projetos, ele também criou uma empresa especializada em suprimentos, mobiliário e serviços para bibliotecas, atualmente conhecida como Library Bureau (WIEGAND, 1996). 
Dewey tornou-se bibliotecário do Columbia College em 1883 e mais adiante, em 1887, fundou na mesma instituição a primeira graduação em Biblioteconomia do mundo, chamada School of Library Economy. Dewey mudouse para Albany em 1889 e levou consigo o curso de graduação que voltou para as dependências de Columbia em 1926 (WIEGAND, 1996). O Bibliotecário assumiu mais tarde o cargo de diretor da Biblioteca do Estado de Nova York e se manteve no posto de 1889 até 1906. Dentre seus feitos pela Biblioteconomia também está sua luta para incluir oportunidades de carreira para mulheres, luta que sua primeira esposa, Annie Dewey, esteve ao seu lado (WIEGAND, 1996).

Vemos então que o impacto de Melvil Dewey na Biblioteconomia é grande. Assim como Panizzi, ele foi um pioneiro em diversas áreas, abrindo espaço para o estudo e formação profissional do bibliotecário. Dewey faleceu em 1931, aos oitenta anos e oito décadas depois sua classificação é o sistema de classificação bibliográfica mais utilizado no mundo (OCLC, 2016).

\section{ANÁLISE DAS IDEIAS}

Segundo Orlandi (2009), a linguagem é uma forma de poder e dominação. Ela comenta que:

Ao procurar explicar a linguagem, o homem está procurando explicar algo que lhe é próprio e que é parte necessária de seu mundo e da sua convivência com os outros seres humanos (ORLANDI, 2009, p. 8).

Ela ainda afirma que a linguagem exerce um fascínio sobre o homem. Podemos notar esse fascínio através da literatura, poesia e filosofia, por exemplo.

Para Orlandi (2009) existem muitas formas de se estudar a linguagem. Podemos concentrar nossa atenção em aspectos como a gramática, ou considerá-la como um sistema de regras formais ou enquanto um sistema de signos. A linguagem pode significar coisas diferentes, assim como seu estudo pode abranger áreas diversas. Justamente por isso alguns estudiosos 
começaram a direcionar suas pesquisas para a linguagem de uma maneira mais particular, que seria o discurso, e assim originou-se a Análise do Discurso (AD).

$\mathrm{Na} A D$ o objetivo é compreender a língua enquanto um trabalho simbólico que faz parte de um trabalho social, que é constitutivo do homem e de sua história. O presente trabalho não irá analisar uma fala ou escrito especifico de cada personagem aqui retratado. $O$ objetivo é analisar um conjunto de ideias sob aspectos ideológicos, históricos e sociais, relacionando-os ao nosso mundo atual.

$A A D$ é a ferramenta ideal, pois ela "concebe a linguagem como mediação necessária entre o homem e a realidade natural e social" (ORLANDI, 2007). Para esse estudo a região do conhecimento da $A D$ que mais se encaixa ao propósito é a teoria da ideologia, já que os recortes são um catálogo e uma classificação, produtos de ideias que foram motivadas por necessidades da sociedade.

Fernandes (2007) diz que o discurso é exterior à linguagem e encontrase no social. Aplicando isso ao objeto de estudo podemos dizer então que o Catálogo de Panizzi e a CDD são produtos de necessidades do meio social, detectadas por Dewey e Panizzi. O Catálogo era necessário, pois, com o crescimento da Biblioteca Britânica, a desordem aumentou, dificultando a recuperação dos volumes e gerando a insatisfação dos usuários. Já no caso da CDD, sua criação não foi feita para um local específico, mas sim para sanar um problema de organização geral que Dewey detectou. As bibliotecas sofriam para encontrar um meio de separar seus assuntos satisfatoriamente e Dewey, enxergando esse problema dentro da comunidade bibliotecária, criou um sistema de regras a fim de sanar as dificuldades.

Em ambos os casos, como Orlandi (2007) afirma, o discurso "produz um conhecimento a partir do próprio texto, porque o vê como tendo uma materialidade simbólica própria e significativa, como tendo uma espessura semântica". De fato, nos dois exemplos é o que acontece, são suportes que produzem e representam o conhecimento e nesses casos ainda é possível afirmar que a materialidade não é apenas simbólica. Ela vai além, pois os suportes realmente têm consigo um meio material. O que está representado ali através da linguagem, está "vivo" fora do catálogo e da classificação. A 
representação está nas prateleiras, organizada exatamente de acordo como foi descrita.

O conhecimento relacionado ao acesso à informação, à organização e à identificação de onde e como encontrar o material necessário é produzido a partir dos textos de classificação e catalogação. Esse é um conhecimento que leva a outro. Ao classificar e catalogar é utilizado um determinado conhecimento para facilitar o acesso a um conhecimento mais amplo: os materiais que estão sendo tratados e organizados.

Dessa forma podemos afirmar que essa atividade é um discurso escrito e organizado em listas sistemáticas, onde são atribuídas classes, temas, assuntos, para melhor falar por uma determinada obra e levar a um discurso mais amplo. Esse discurso mais amplo são as obras em si. São os livros, por exemplo, que estão representados por essas classificação e catalogações. É necessário um conhecimento para realizar essas atividades, para encontrar o material necessário e para aprecia-lo depois. Junto desse conhecimento temos o discurso, que fala sobre o meio em que toda essa organização foi criada e que um determinado acervo foi montado.

Orlandi (2007, p. 21) ainda reflete:

[...] diremos que não se trata de transmissão de informação apenas, pois, no funcionamento da linguagem, que põe em relação sujeitos e sentidos afetados pela língua e pela história, temos um complexo processo de constituição desses sujeitos e produção de sentidos e não meramente transmissão de informação.

Realmente, não se trata apenas de transmissão. Essa pode ser considerada a função principal tanto da classificação quanto do catálogo, ambos têm como objetivo transmitir informações. Mas, no entanto, como foi dito, esse é um processo complexo que envolve a sociedade, a língua e a história. A partir disso se dá a constituição do sujeito, que nesse caso, são o catálogo e a classificação, que são produtores de sentido e não meramente transmissores de informação. 
Os dois não são meramente transmissores de informação porque representam um amplo conjunto de assuntos, possibilitam sua organização e principalmente a recuperação da informação. Não é o caso de apenas passar a informação adiante, é detectar uma necessidade a respeito de um tópico especifico, recuperar esse tópico e disponibilizá-lo.

Pêcheux comenta o sentido do enunciado considerando dois pontos distintos em interlocução que exemplifica o que foi discutido até então:

[...] Trata-se se um 'efeito de sentidos' entre os pontos A e B. [...] Os elementos $A$ e $B$ designam algo diferente da presença física de organismos humanos individuais. [...] A e B designam lugares determinados na estrutura de uma formação social (PÊCHEUX; FUCHS, 1990, p.169).

O exemplo pode se encaixar no que se diz respeito ao catálogo e à classificação tomando por ' $A$ ' as obras que são representadas em seus conteúdos (do catálogo e da classificação) e sendo 'B' o próprio catálogo e a classificação. Há um efeito de sentidos entre os pontos, de modo que a obra está representada no catálogo ou classificação para demonstrar sua presença em um determinado acervo. $\mathrm{O}$ acervo pode ser pensado como a estrutura de uma formação social, pois sua construção nada mais é do que a representação de gostos, necessidades e estudos de uma sociedade naquele momento.

Esse lugar social em que os catálogos e classificações se encontram definem as condições de produção e compreendem fundamentalmente os sujeitos e a situação (ORLANDI, 2007). Outra parte dessa produção é a memória. Ela influencia como um interdiscurso, como algo que fala antes da produção, afetando o modo como uma situação é significada e como essa produção, que nesse caso é de conhecimento, será feita.

Junto da memória há também a historicidade, que determinará aquilo que, da situação e das condições de produção, será relevante para o discurso. É a historicidade que especifica as condições nas quais um acontecimento histórico vai se inscrever na história e se vai virar memória (ORLANDI, 2007). Através da historicidade o catálogo e a classificação em questão poderiam ou não ter permanecido como grandes ideias da Biblioteconomia. 
Assim, para Orlandi (2007), isso tudo não se origina em nós, nós é que entramos nesse processo. Isso se faz verdade nesse caso, pois ambos os exemplos continuam vivos na rotina do bibliotecário atual, mantidos pelo 'nós'. Segundo Orlandi (2007, p. 35): "eles se realizam em nós sua materialidade". Nesse caso eles realizam através da classe bibliotecária e dos trabalhos de catalogação e classificação sua materialidade. Ela ainda diz que "é dessa maneira que sentidos e sujeitos estão sempre em movimento, significando de muitas e variadas maneiras" (ORLANDI, 2007, p. 36).

Podemos dizer então que a soma da historicidade, da memória criada e do discurso entre a sociedade e essas criações deram o resultado que vemos atualmente: um catálogo que influenciou diversos outros e ainda é um modelo moderno importante e uma classificação que é amplamente utilizada até os dias de hoje.

\section{CONSIDERAÇÕES FINAIS}

Ao olhar para o passado, é possível ver que essas ideias foram revolucionarias e estiveram à frente do seu tempo. Ainda hoje, apesar de nossos modelos mais atuais e tecnologias que facilitam a rotina, eles ainda se fazem presente.

Dewey deixou um legado que atualmente se encontra em sua vigésima terceira edição, é constantemente ampliado e atualizado. Possui uma ferramenta digital que pode substituir a edição física e é considerada a classificação mais utilizada no mundo.

Panizzi por sua vez não conseguiu com que seu catálogo tivesse edições revistas e continuasse em uso, mas influenciou importantes catálogos contemporâneos ao seu e outros depois, chegando até a influenciar os modos de catalogação em sistemas como a AACR2, também amplamente utilizada até os dias de hoje.

Os dois bibliotecários descritos parecem estar distantes, suas ideias parecem não fazer parte de um mesmo círculo, mas como o presente trabalho procurou mostrar, estão intimamente ligadas. Panizzi buscou uma forma mais 
simples de se recuperar a informação dentro de um acervo de grande porte, Dewey procurou uma forma simples de separar assuntos e tópicos para ser possível organizar a informação de maneira mais precisa.

O que é visto atualmente em uso é simplesmente uma soma das suas ideias: classifica-se com mais precisão, colocando as obras o mais próximo possível de suas temáticas e ao classificar com precisão, coloca-se essas obras em um catálogo que terá informações mais bem construídas. Esse catálogo soma a classificação com outras informações importantes e possibilita uma recuperação mais efetiva de acordo com as necessidades do usuário.

O que é visto hoje na Biblioteconomia moderna é uma conversa constante entre os dois bibliotecários de antigamente. São dois discursos convivendo em harmonia e interligados pelas necessidades sociais.

\section{REFERÊNCIAS}

FAGAN, Louis. The life of sir Anthony Panizzi: late principal librarian of the British Museum, Senator of Italy, Etc. Cambridge: Cambridge University Press, 2012.

FATTAHI, Ramat. The relevance of cataloguing principles to the online environment: an historical and analytical study. 1997. These (doctorate) School of Information, Library and Archive Studies, University of New South Wales, Australia, 1997.

FERNANDES, Cleudemar Alves. Análise do discurso: reflexões introdutórias. São Carlos: Editora Claraluz, 2007.

MILLER, Edward. Prince of librarians: the life and times of Antonio Panizzi of the British Museum. Athens: Ohio University Press, 1967.

OCLC. Serviços Dewey. Organize your materials with the world's most widely used library classification system. 2016. Disponível em: <https://www.oclc.org/ dewey.en.html>. Acesso em: 12 jan. 2016.

ORLANDI, Eni P. Análise do discurso: princípios e procedimentos. Campinas: Editora Pontes, 2007.

ORLANDI, Eni, P. O que é linguística. 2. ed. São Paulo: Brsiliense, 2009. 
ORTEGA, Cristina Dotta. Relações históricas entre Biblioteconomia, Documentação e Ciência da Informação. DataGramaZero, Rio de Janeiro, v. 5, n. 5, out. 2004. Disponível em: < http://www.dgzero.org/out04/Art_03.htm>. Acesso em: 12 jan. 2016.

PÊCHEUX, Michel; FUCHS, Catherine. A propósito da análise automática do discurso: atualização e perspectivas. In: GADET, Françoise; HAK, Tony (Org.). Por uma análise automática do discurso: uma introdução à obra de Michel Pêcheux. Campinas, SP: Ed. Unicamp, 1997. p.163-252.

WIEGAND, Wayne A. A biography of Melvil Dewey: irrepresible reformer. Chicago: American Library Association, 1996.

\title{
THE RELATION BETWEEN PANIZZI AND DEWEY: A DISCURSIVE ANALYSIS ABOUT THEIR CREATIONS AND THE MODERN LIBRARIANSHIP.
}

\begin{abstract}
Introduction: Librarianship has been developing, especially since the nineteenth century with the creation of the first schools and the development of more elaborate rules and systems of organization. Objective: This article aims at a comparative study between two of the most important librarians in history and who brought innovations in this century. Antony Panizzi, creator of the British Museum's Catalog of Printed Books, better known as the Panizzi Catalog, which organized the entire British Museum Library in 1837, and Melvil Dewey, creator of the Dewey Decimal Classification in 1876, used to date and considered of the most popular rating methods in the world. Both were pioneers in the history of Librarianship and organization of information, one in catalogs and the other in classifications. Although they have modified different areas, they are related, and the paths of librarians have several points in common. Methodology: This study will discuss, with the help of discourse analysis and its theorists, the importance of the creations of these two librarians and how they are then linked and completed. Results: The two librarians described seem to be distant, their ideas do not seem to belong to the same circle, but as the present work shows, they are closely linked. Conclusions: The creations of both are still present in our routine activities and have aided in the development of current techniques and systems, showing that Librarianship has a strong base in their past that assists in the construction of their future
\end{abstract}

Descriptors: Antony Panizzi. Melvil Dewey. Catalogue. Discourse analysis. Librarianship. 


\title{
LAS RELACIONES ENTRE PANIZZI Y DEWEY: UN ANÁLISIS DISCURSIVO SOBRE SUS CREACIONES Y LA BIBLIOTECONOMÍA MODERNA
}

\begin{abstract}
RESUMEN
Introducción: La Biblioteconomía se viene desarrollando, principalmente, desde el siglo XIX con la creación de las primeras escuelas y el desarrollo de reglas y sistemas más elaborados de organización. Objetivo: El presente artículo tiene como objetivo un estudio comparativo entre dos de los más importantes bibliotecarios de la historia y que trajeron innovaciones en ese siglo. Antony Panizzi, creador del Catálogo de los Libros Impresos del Museo Británico, más conocido como Catálogo de Panizzi, que organizó toda la Biblioteca del Museo Británico en 1837, y Melvil Dewey, creador de la Clasificación Decimal Dewey, en 1876, utilizada hasta hoy y considerada un " de los métodos de clasificación más populares en todo el mundo. Ambos fueron pioneros en la historia de la Biblioteconomía y en la organización de la información, uno en los catálogos y el otro en las clasificaciones. Aunque han modificado áreas diferentes, están relacionadas, y las trayectorias de los bibliotecarios tienen diversos puntos en común. Metodología: Este estudio discutirá, con la ayuda del análisis del discurso y sus teóricos, la importancia de las creaciones de estos dos bibliotecarios y cómo ellas entonces ligadas y se completan. Resultados: Los dos bibliotecarios descritos parecen estar distantes, sus ideas parecen no formar parte de un mismo círculo, pero como el presente trabajo muestra, están íntimamente ligadas. Conclusiones: Las creaciones de ambos todavía están presentes en nuestras actividades rutinarias y ayudan en el desarrollo de técnicas y sistemas actuales, mostrando que la Biblioteconomía tiene una base fuerte en su pasado que auxilia en la construcción de su futuro.
\end{abstract}

Descriptores: Antony Panizzi. Melvil Dewey. Catálogo. Análisis del discurso. Biblioteconomía. 